THERMAL STABILITY AND MECHANICAL BEHAVIOR OF ULTRA-FINE BCC TA AND V COATINGS

A. F. Jankowski, J. Go, J. P. Hayes

November 3, 2006

International Conference on Metallurgical Coatings and Thin Films

San Diego, CA, United States

April 23, 2007 through April 27, 2007 
This document was prepared as an account of work sponsored by an agency of the United States Government. Neither the United States Government nor the University of California nor any of their employees, makes any warranty, express or implied, or assumes any legal liability or responsibility for the accuracy, completeness, or usefulness of any information, apparatus, product, or process disclosed, or represents that its use would not infringe privately owned rights. Reference herein to any specific commercial product, process, or service by trade name, trademark, manufacturer, or otherwise, does not necessarily constitute or imply its endorsement, recommendation, or favoring by the United States Government or the University of California. The views and opinions of authors expressed herein do not necessarily state or reflect those of the United States Government or the University of California, and shall not be used for advertising or product endorsement purposes. 


\title{
Thermal stability and mechanical behavior of ultra-fine bcc Ta and V coatings
}

\author{
Alan F. Jankowski, Jackson Go, and Jeffrey P. Hayes \\ Lawrence Livermore National Laboratory \\ Chemistry, Materials, and Life Sciences Department \\ P.O. Box 808, MS L-352, Livermore, CA 94550
}

\begin{abstract}
Ultra-refined microstructures of both tantalum (Ta) and vanadium (V) are produced using electron-beam evaporation and magnetron sputtering deposition. The thermal stability of the micron-to-submicron grain size foils is examined to quantify the kinetics and activation energy of diffusion, as well as identify the temperature transition in dominant mechanism from grain boundary to lattice diffusion. The activation energies for boundary diffusion in Ta and V determined from grain growth are 0.3 and $0.2 \mathrm{eV} \cdot$ atom $^{-1}$, respectively, versus lattice diffusion values of 4.3 and $3.2 \mathrm{eV} \cdot$ atom $^{-1}$, respectively. The mechanical behavior, as characterized by strength and hardness, is found to inversely scale with square-root grain size according to the Hall-Petch relationship. The strength of Ta and V increases two-fold from $400 \mathrm{MPa}$, as the grain size decreases from 2 to $0.75 \mu \mathrm{m}$.
\end{abstract}

KEY WORDS: sputtering; evaporation; tantalum; vanadium; stress; hardness; diffusion

\section{INTRODUCTION}

The fine grain structure of pure metal coatings can be thermally unstable. At the micron to submicron scale, ultra-refined microstructures of the body-centered-cubic (bcc) metals, tantalum 
(Ta) and vanadium (V) are produced using methods of physical vapor deposition (PVD).

Specifically, magnetron sputtering ${ }^{[1]}$ and electron-beam evaporation ${ }^{[2]}$ processes prove advantageous to deposit metals with high melt temperatures $\left(\mathrm{T}_{\mathrm{m}}\right)$ as fully-dense, thick coatings. Samples in the form of free-standing foils are characterized in the as-deposited condition and subsequent to high-temperature vacuum anneal treatments to quantify the kinetics of diffusion for grain growth. Grain size is determined from optical micrographs of cross-sections by linear intercept measurements. The diffusivity and activation energy for grain growth are determined, identifying the temperature transition in dominant mechanism from grain boundary to hightemperature isotope reference values ${ }^{[3-4]}$ for lattice diffusion.

$\mathrm{Ta}$ and $\mathrm{V}$ metal, in the form of coatings, nanolaminates, and bulk material with nanoscale grain size, are reported to show ${ }^{[5-7]}$ an increase in strength and microhardness by a order-ofmagnitude above fully homogenized materials. This regime of grain size intermediate to the macroand nano-scale is assessed to examine effects on strength, hardness, and scaling of the Hall-Petch relationship in the body-centered-cubic (bcc) phase of Ta and V. Sample strength is measured under uniaxial tension using a pull tester, and hardness is measured by Vickers microindentation.

\section{EXPERIMENTAL METHODS}

Ta and V foils are initially prepared by the PVD methods of electron-beam evaporation and magnetron sputtering. Coatings of 10-50 $\mu \mathrm{m}$ are deposited onto sheets of muscovite. The substrates are subsequently peeled away to yield free-standing metal foils. The sputter deposition of the coatings utilizes planar magnetrons of $6.35-7.62 \mathrm{~cm}$ diameter. The sputter sources are operated in the dc mode using an ultra-high purity, working-gas of Argon from the boil off of liquid Argon. The control of substrate temperature ${ }^{[8]}$ and the energetic sputtered neutral ${ }^{[9]}$ is key to deposition of fully 
dense coatings. A Ta platen is resistively heated onto which the muscovite substrates are clamped. The coating temperature is measured using a thermocouple on the substrate side exposed to the deposition flux. The deposition temperature for the sputter deposits is less than $800 \mathrm{~K}$, whereas heating up to $1500 \mathrm{~K}$ is used for evaporated coatings. For sputtering, the source to substrate separation is kept minimal at $<8 \mathrm{~cm}$, just beyond the hot electron sheath above the 0.9999 pure target, to provide the condition ${ }^{[10-11]}$ for energetic sputtered neutrals.

The high-temperature anneal treatments are conducted using a quartz tube evacuated using a turbomolecular pump to a base pressure of $1.1 \cdot 10^{-6} \mathrm{~Pa}$. The quartz tube is placed within a clam-shell Lindberg furnace for resistive heating to $1473 \mathrm{~K}$. A pressure no greater than $2 \cdot 10^{-5} \mathrm{~Pa}$ is maintained throughout the anneal cycle. The foil microstructure is revealed in micrographs of specimens prepared in cross-section. Optical and scanning-electron microscopes are used in imaging. Grain size $\left(d_{g}\right)$ is determined using the conventional, lineal-intercept method. X-ray diffraction in the $\theta / 2 \theta$ mode is used for the identification of crystalline phase and film texture analysis. Mechanical property measurements include Vickers microhardness and uniaxial pull testing. Tensile specimens are cut to shape from free-standing foils using an excimer laser. This method ensures a sharp and smooth specimen edge without damage as can be encountered for mechanical cutting procedures. Samples have a 3:1 gage length-to-width ratio consistent with ASTM standards. A laser extensometer is used to measure changes in the $1 \mathrm{~cm}$ gage length with applied strain rates of $5 \cdot 10^{-5}$ to $10^{-4} \mathrm{sec}^{-1}$.

\section{AnAlytic Methods}

The coating grain size will vary as function of temperature, i.e. an isothermal temperature

(T) during deposition as well as for post-deposition anneal treatments. The grain growth law ${ }^{[12]}$ 
provides the relationship to compute the activation energy $(\mathrm{Q})$ needed for grain growth. The law relates grain size $\left(d_{g}\right)$ to time $(t)$ raised to the power $\mathrm{n}$, as in the expression

$$
d_{g}=t^{\mathrm{n}}
$$

A linear relationship for the variation of $\Delta d_{g}{ }^{2}$ with $\mathrm{t}$ confirms ideal grain growth ${ }^{[2]}$, i.e. where $\mathrm{n}$ equals 0.5 . The change in grain size squared $\left(\Delta d_{g}{ }^{2}\right)$ is then determined as,

$$
\Delta d_{g}^{2}=\left(d_{g}^{\mathrm{f}}\right)^{2}-\left(d_{g}^{\mathrm{i}}\right)^{2}
$$

where $d_{g}{ }^{\mathrm{i}}$ is the initial grain size and $d_{g}{ }^{\mathrm{f}}$ is the final grain size. The activation energy (Q) is determined from the classic relationship ${ }^{[13]}$,

$$
\mathrm{Q}=-\mathrm{R} \cdot\left[\ln \left(\Delta d_{g}^{2} \cdot t^{-1}\right)\right] \cdot\left[\mathrm{T}_{\mathrm{c}}^{-1}\right]^{-1}
$$

A plot of $\mathrm{T}^{-1}$ versus $\ln \left(\Delta d_{g}^{2} \cdot t^{-1}\right)$ should yield a linear variation from which a value for the slope equals $\left\{-\mathrm{Q} \cdot(\mathrm{R})^{-1}\right\}$, noting that $\mathrm{R}$ is the molar gas constant $\left(8.314 \mathrm{~J} \cdot \mathrm{mol}^{-1} \cdot \mathrm{K}^{-1}\right)$. A linear regression analysis is used to compute the $\mathrm{Q}$ wherein the correlation coefficient $\left(\mathrm{R}^{2}\right)$ quantifies variation from an ideal straight line. The time of the anneal treatment is used in determining grain growth whereas the time of deposition is used to determine the initial grain size.

In general, the strength and hardness of metals is known to increase with decreasing grain size at the macroscale according to the Hall-Petch relationship ${ }^{[14-16]}$. For the case of hardness, this relationship is written as

$$
\Delta \mathrm{H}=\mathrm{H}-\mathrm{H}_{\mathrm{o}}=k_{H} \cdot h^{-0.5}
$$

where $\mathrm{H}_{\mathrm{o}}$ is the value for fully homogenized, large grain samples, $h$ is the dimensional feature of size (i.e. grain size $d_{g}$ for the present study), $k_{H}$ is a material specific constant, and $\mathrm{H}$ is measured 
hardness. For Vickers microhardness testing, the baseline hardness value of $\mathrm{H}_{\mathrm{o}}$ is approached as the indent size becomes roughly equivalent to the grain size at a few microns. Similarly, an expression for strength $(\sigma)$ is written as

$$
\Delta \sigma=\sigma-\sigma_{\mathrm{o}}=k_{\sigma} \cdot h^{-0.5}
$$

It's interpreted ${ }^{[16]}$ that the $k_{\sigma} \cdot d_{g}^{-0.5}$ term of eqns. (4-5) represents the grain boundary resistance to slip propagation. For bec metals as Ta and V, the important influence ${ }^{[16]}$ on uniform strain is the Peierls-Nabarro ${ }^{[17-18]}$ stress, i.e. any intrinsic resistance due to the dislocation structure.

\section{Results AND AnALysis}

\section{Deposition and Microstructure}

The sputtered thickness output is determined for the planar magnetron sources operated at 300-350 W forward power with a discharge of 295-430 V. The control of the residual stress state in the sputtered deposits is accomplished by optimizing the working gas pressure. Typically, a transition in the residual state of the coating from compression to tension is found, as for example in $\mathrm{Ta}^{[19]}$, as the gas pressure is increased. At a source-to-substrate separation of $7.3 \mathrm{~cm}$, a working gas pressure of $1.06-1.33 \mathrm{~Pa}$ with a $28-35 \mathrm{~cm}^{3} \cdot \mathrm{m}^{-1}$ flow is found to yield stress-free deposits, similar to the parameters used ${ }^{[19-20]}$ for sputter depositing Ta and Ta-Al multlilayer composites. The Ta and V target output in Fig. 1 is plotted as the product of forward power $(P)$ with deposition time $(t)$ in a power law relationship with coating thickness $(\boldsymbol{\ell})$ as

$$
P \cdot t=c \cdot(\ell)^{n}
$$


where $c$ is a material constant, and $n$ is the power-law exponent. For Ta, $n$ equals 1.035 and increases to 1.233 for $\mathrm{V}$ as the lighter element scatters more.

The microstructure typical of coatings in the as-deposited condition and subsequent to a thermal anneal treatment are shown in Fig. 2. The foils are polished and lightly etched to reveal grain boundary structure. For the example of a V foil (shown in Fig. 2a) that was electron-beam deposited at $841 \mathrm{~K}$ in $5 \mathrm{~m}$, a grain size of $0.79 \pm 0.05 \mu \mathrm{m}$ is measured by the lineal-intercept method. After a $432 \mathrm{~m}$ vacuum anneal at $1370 \mathrm{~K}$, the grain size has coarsened (shown in Fig. $2 \mathrm{~b}$ ) to $2.66 \pm 0.31 \mu \mathrm{m}$. Prior $\mathrm{x}$-ray diffraction characterization ${ }^{[1]}$ indicates that these Ta and $\mathrm{V}$ foils have a (110) textured body-centered-cubic (bcc) growth.

\section{Grain Growth and Diffusion}

The results of the grain size measurements for as-deposited Ta foils (solid diamond) and V foils (open circle) are plotted in Fig. 3. Curves are drawn from tracer-isotope data of $\mathrm{Ta}^{182}$ in $\mathrm{Ta}$ (open diamond) over 1523-2473 K, and $\mathrm{V}^{48}$ in $\mathrm{V}$ (solid circle) over 1153-1633 K. The results for the high-temperature vacuum annealed V foils (shaded circles) are plotted as well, clearly matching the linear curve drawn from $\mathrm{V}$ isotope diffusion. The activation energy $\left(\mathrm{Q}_{\mathrm{v}}\right)$ for the lattice (or volume) diffusion mechanism, as computed using the relationship of eqn. (3), are $\mathrm{Q}_{\mathrm{v}}{ }^{\mathrm{Ta}}$ equals 4.26 $\mathrm{eV} \cdot$ atom $^{-1}$ and $\mathrm{Q}_{\mathrm{v}}{ }^{\mathrm{V}}$ equals $3.19 \mathrm{eV} \cdot \mathrm{atom}^{-1}$. In comparison, the activation energy $\left(\mathrm{Q}_{\mathrm{gb}}\right)$ for grain boundary diffusion equal $0.29 \mathrm{eV} \cdot$ atom $^{-1}$ for $\mathrm{Qgb}^{\mathrm{Ta}}$ and $0.19 \mathrm{eV} \cdot \mathrm{atom}^{-1}$ for $\mathrm{Qgb}_{\mathrm{gb}} \mathrm{V}$. The temperature transition from (low temperature) grain boundary to (high temperature) lattice diffusion in these PVD foils is rather marked as the slope changes by several multiples between distinct linear regimes at $\mathrm{T}$ greater than: $\sim 1260 \mathrm{~K}$ for $\mathrm{V}$ which is $\sim 58 \%$ the $2163 \mathrm{~K}$ melt temperature $\left(\mathrm{T}_{\mathrm{m}}{ }^{\mathrm{V}}\right)$; and $1540 \mathrm{~K}$ for Ta which is $47 \%$ the $3269 \mathrm{~K}$ melt temperature $\left(\mathrm{T}_{\mathrm{m}}{ }^{\mathrm{Ta}}\right)$.

The change in slope between the two linear regimes for each metal confirms a change in the dominant mechanism for grain growth - that is, from dislocation (i.e. grain boundary) to volume 
(i.e. lattice) diffusion as the coating temperature increases. The difference between the two activation energies for the high and low temperature regimes by a factor of two or more is in agreement with a compilation of findings ${ }^{[21]}$ by Martin and Perraillon. They note for the case of self-diffusion, which applies high-temperature grain growth, that the apparent activation energy in a grain boundary is roughly $0.4-0.6$ times the activation energy for bulk diffusion.

\section{Mechanical Properties}

The Vickers microhardness $\left(\mathrm{H}_{\mathrm{v}}\right)$ is determined from Vickers indentations of the polished cross-sections using a $5 \mathrm{~g}$ force load. These measurements are representative of the bulk polycrystal since the PVD Ta and V foils have texture but are randomly oriented ${ }^{[1]}$ with respect to the in-plane section. The Fig. 4 plot of $\mathrm{H}_{\mathrm{v}}$ with the inverse-square root of grain size $\left(d_{g}^{-0.5}\right)$ yield linear curves over the grain size range of $0.7-4 \mu \mathrm{m}$ for Ta as well as for the $\mathrm{V}$ foils. For Ta, as from eqn. (4), $k_{H}{ }^{T a}$ equals $2.85 \mathrm{GPa}-\mu \mathrm{m}^{0.5}$ where $\mathrm{R}^{2}$ equals 0.95 . Similarly for $\mathrm{V}, k_{H}{ }^{V}$ equals $\sim 2.15 \mathrm{GPa}-\mu \mathrm{m}^{0.5}$ where $\mathrm{R}^{2}$ equals 0.84 indicating some statistical scatter in the data. The $\mathrm{H}_{\mathrm{o}}{ }^{\mathrm{Ta}}$ and $\mathrm{H}_{\mathrm{o}}{ }^{\mathrm{V}}$ values both approach 1 GPa over this grain size regime.

The fracture surfaces of $15 \mu \mathrm{m}$ thick $\mathrm{V}$ tensile specimens tested at room temperature are shown in Fig. 5 as imaged using secondary electrons in a scanning electron microscope. The Fig. 5a image of a sputter deposited foil reveals intergranular features. The Fig. $5 \mathrm{~b}$ image of an evaporative deposit reveals the ductile dimple features of an intragranular fracture. The intrinsic ductility of these different failure modes in tension is seen in Fig. 6 for typical engineering stress - engineering strain curves of $\mathrm{V}$ foils tested under uniaxial tension at strain rates of $5 \cdot 10^{-5}$ to $1 \cdot 10^{-4} \mathrm{sec}^{-1}$. The 26 $\mu \mathrm{m}$ thick, sputter deposited $\mathrm{V}$ foil with a $0.55 \mu \mathrm{m}$ grain size has a $742 \mathrm{MPa}$ yield point at $0.83 \%$ strain with an ultimate strength of $778 \mathrm{MPa}$ at $1.07 \%$ strain. The $36 \mu \mathrm{m}$ thick, electron-beam deposited V foil with a $1.61 \mu \mathrm{m}$ grain size has an initial yield point of $384 \mathrm{MPa}$ at $0.14 \%$ strain with 
an ultimate strength of $479 \mathrm{MPa}$ at $8.75 \%$ strain. A Hall-Petch plot for both Ta and V strength results is shown in Fig. 7 wherein the $k_{\sigma}{ }^{T a}$ equals $556 \mathrm{MPa}-\mu \mathrm{m}^{0.5}$ with $\mathrm{R}^{2}$ equaling 0.998 and similarly for $\mathrm{V}, k_{\sigma}{ }^{V}$ equals $476 \mathrm{MPa}-\mu \mathrm{m}^{0.5}$ with $\mathrm{R}^{2}$ equaling 0.993 . Although, the strain to failure may vary fom sample to sample, there is no distinction between the strength of sputter deposited and electron-beam evaporated foils with the same grain size. The linear curves of Fig. 7 are fit with values for fully homogenized Ta and $\mathrm{V}$ yielding values for ${\sigma_{\mathrm{o}}}^{\mathrm{Ta}}$ and $\sigma_{\mathrm{o}}{ }^{\mathrm{V}}$ are 152 and $106 \mathrm{MPa}$, respectively. For example, the tensile strength of cast vanadium with a $35 \mu \mathrm{m}$ grain size is reported ${ }^{[22]}$ as $197 \mathrm{MPa}$. Also, values of strength are reported ${ }^{[23]}$ for large grain Ta samples reprocessed by casting in high vacuum at $\sim 180 \mathrm{MPa}$. The increase in strength observed for the $\mathrm{V}$ foils at present is similar to the values reported ${ }^{[24]}$ for wire and sheet stock that has been cold drawn or cold rolled from its vacuum annealed condition.

\section{SUMMARY}

Ultra-refined microstructures of both tantalum $(\mathrm{Ta})$ and vanadium $(\mathrm{V})$ are produced using the physical vapor deposition (PVD) methods of electron-beam evaporation and magnetron sputtering deposition. The target output from magnetron sputtering is the product of forward power with deposition time which varies, in a power law relationship, with coating thickness. The powerlaw exponent equals 1.035 for $\mathrm{Ta}$, and increases to 1.233 for $\mathrm{V}$ as the lighter element scatters more in the working gas.

The thermal stability of the micron-to-submicron grain size foils quantifies the kinetics and activation energy of diffusion through an examination of grain growth from thermal anneal treatments. The activation energies for boundary diffusion in Ta and $\mathrm{V}$ are 0.3 and $0.2 \mathrm{eV} \cdot$ atom $^{-1}$,

respectively, versus lattice diffusion values of 4.3 and $3.2 \mathrm{eV} \cdot$ atom $^{-1}$, respectively. The temperature 
transition in the dominant mechanism from grain boundary to lattice diffusion occurs at $1540 \mathrm{~K}$ $\left(0.47 \cdot \mathrm{T}_{\mathrm{m}}{ }^{\mathrm{Ta}}\right)$ for Ta and at $\sim 1260 \mathrm{~K}\left(0.58 \cdot \mathrm{T}_{\mathrm{m}}{ }^{\mathrm{V}}\right)$ for $\mathrm{V}$.

The mechanical behaviors of tensile strength and Vickers microhardness are both found to inversely scale with square-root grain size following the Hall-Petch relationship. For example, the strength of both sputter deposited and electron-beam evaporated V foils increase from 400 to 800 $\mathrm{MPa}$ as the grain size decreases from 2 to $0.75 \mu \mathrm{m}$.

\section{ACKNOWLEDGMENTS}

The authors thank Jim Ferreira for the scanning electron microscopy imaging of specimen cross-sections, Cheng Saw for performing x-ray diffraction scans, as well as James MํNaney and Yin Min Wang for performing some of the tensile tests at low strain rate. This work was performed under the auspices of the U.S. Department of Energy by the University of California, Lawrence Livermore National Laboratory under contract No. W-7405-Eng-48.

\section{REFERENCES}

1. A.F. Jankowski, J.P. Hayes, C.K. Saw, R.F. Vallier, J. Go and R.A. Bliss, TMS Letters 1 (2004) 175

2. A.F. Jankowski, J.L. Ferreira and J.P. Hayes, Thin Solid Films 491 (2005) 61

3. R.E. Pawel and T.S. Lundy, J. Phys. Chem. Solids 26 (1965) 937

4. R.F. Peart, J. Phys. Chem. Solids 26 (1965) 1853

5. Q. Wei, T. Jiao, K.T. Ramesh and E. Ma, Scripta Materialia 50 (2004) 359

6. M. Zhang, B. Yang, J. Chu and T.G. Nieh, Scripta Materialia 54 (2006) 1227 
7. A.F. Jankowski, J.P. Hayes and C.K. Saw, Lawrence Livermore National Laboratory Report UCRL-JRNL-223669, Livermore, CA (2006) 25 pages

8. R.F. Bunshah and R.S. Juntz, Met. Trans. 4 (1973) 21

9. J.A. Thornton, J. Vac. Sci. Technol. 11 (1974) 814

10. W.D. Westwood, J. Vac. Sci. Technol. 15 (1978) 1

11. R.E. Somekh, J. Vac. Sci. Technol. A 2 (1984) 1285

12. R.E. Reed-Hill, Physical Metallurgy Principles, Van Nostrand, New York, NY (1973) 304-310

13. P. Feltham and G.J. Copley, Acta Metallurgica 6 (1958) 539

14. E.O. Hall, Proc. Phys. Soc. B 64 (1951) 747

15. N.J. Petch, J. Iron Steel Inst. 174 (1953) 174

16. R.M. Douthwaite and N.J. Petch, Acta Metallurgica 18 (1970) 211

17. R.E. Peierls, Proc. Phys. Soc. London 52 (1940) 23

18. F.R.N. Nabarro, Proc. Phys. Soc. London 59 (1947) 256

19. A.F. Jankowski, R.M. Bionta and P.C. Gabriele, J. Vac. Sci. Technol. A 7 (1989) 210

20. J.A. Thornton and D.W. Hoffman, J. Vac. Sci. Technol. 14 (1977) 164

21. G. Martin and B. Perraillon, in Grain Boundary Structure and Kinetics, ASM Materials Science Seminar, ASM, Metals Park, OH (1979) 239

22. V.M. Amonenko, M.P. Zeidlits, L.N. Ryabchikov, and S.V. Shevchenko, Strength of Materials $11(1979) 297$

23. M. Schussler, in ASM Handbook, Vol. 2, Metals Park, OH (1993) 1163

24. F.H. Perfect, in ASM Handbook, Vol. 2, Metals Park, OH (1993) 1173 


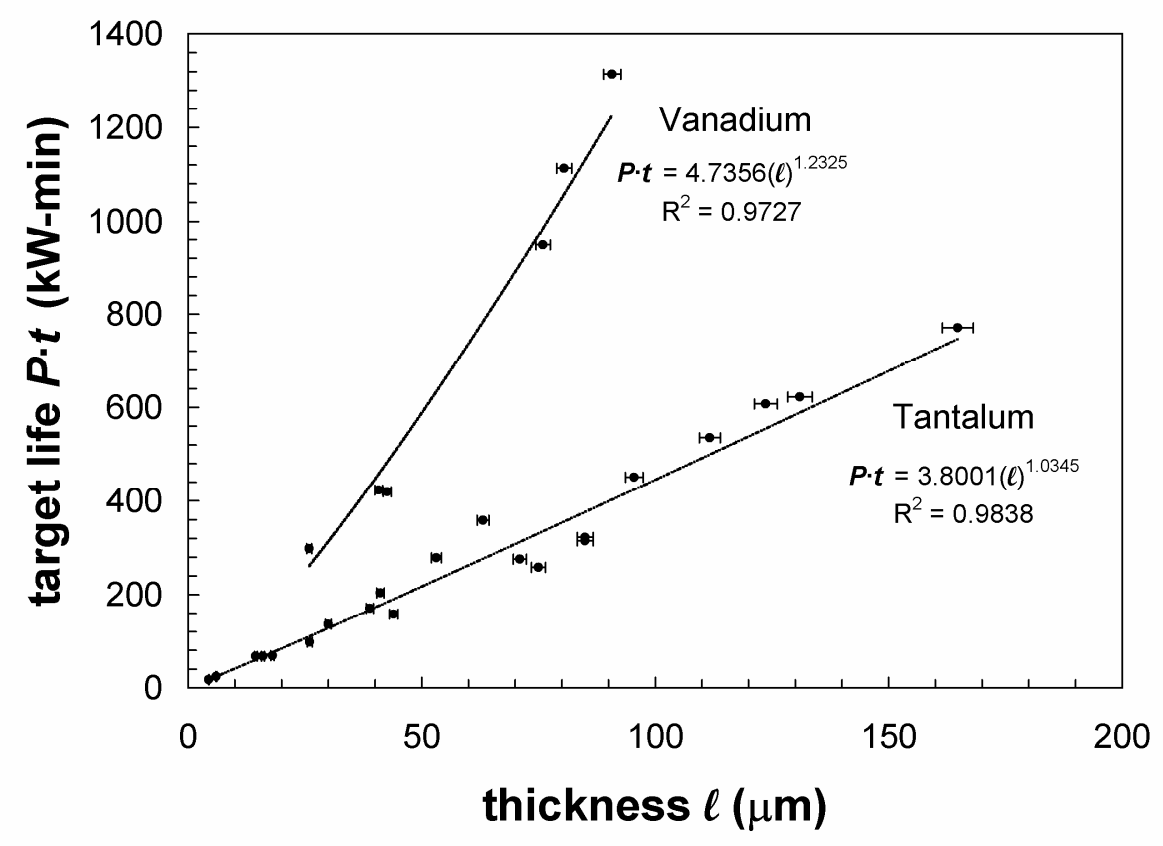

Figure 1. The Ta and $\mathrm{V}$ target output is plotted as the product of forward power $(P)$ with deposition time $(t)$ in a power law relationship with coating thickness $(\boldsymbol{\ell})$.

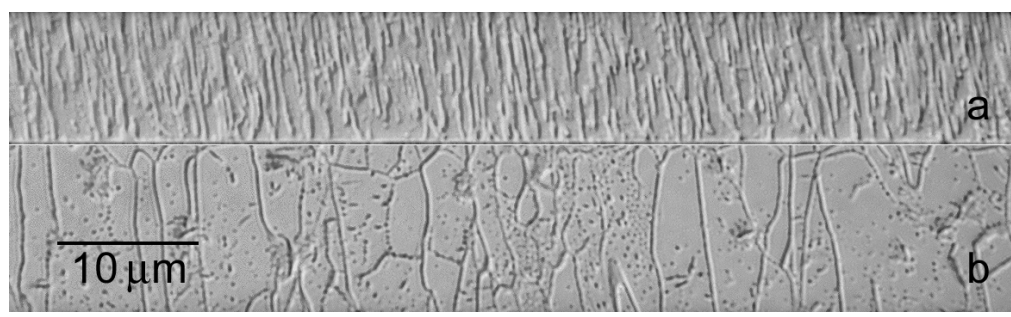

Figure 2. Optical micrographs of a V foil, as viewed in cross-section, are shown of (a) an electronbeam deposit at $841 \mathrm{~K}$ in $5 \mathrm{~m}$, and (b) after a $432 \mathrm{~m}$ vacuum anneal at $1370 \mathrm{~K}$. 


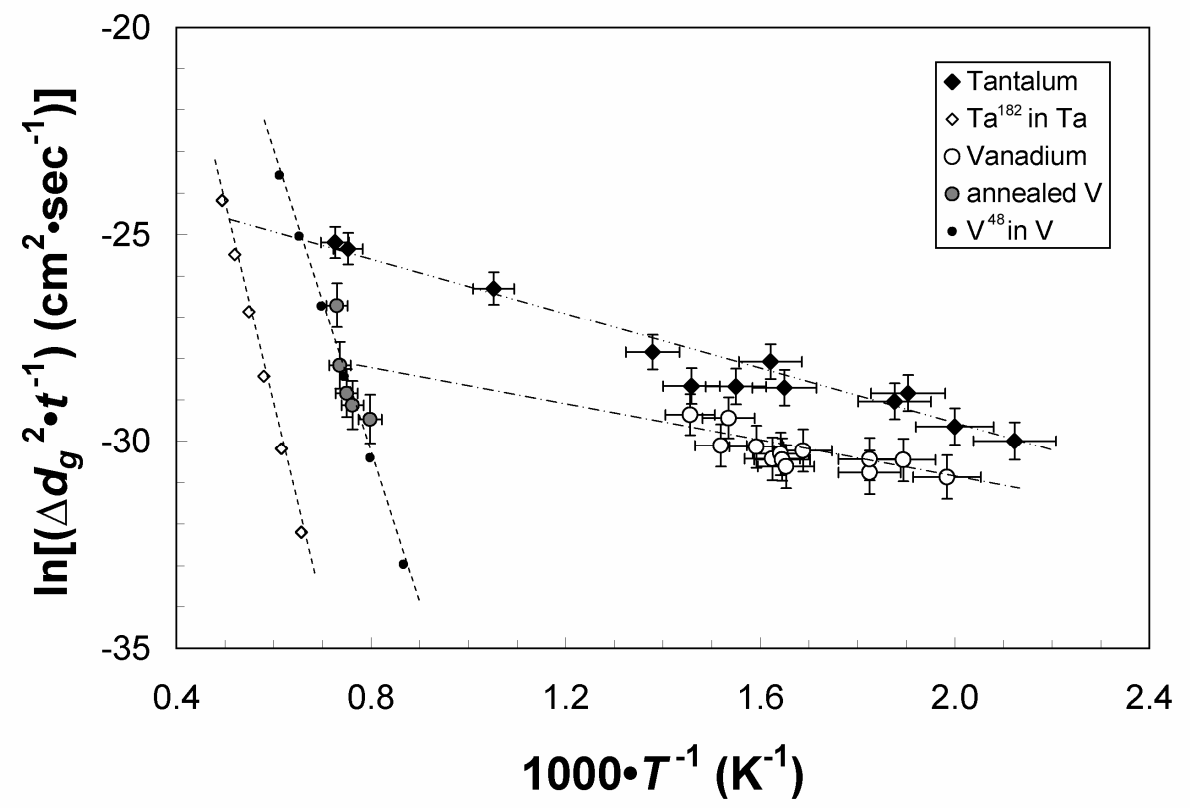

Figure 3. The determination of activation energy for diffusion in $\mathrm{V}$ and Ta foils is achieved using an Arrhenius plot of inverse temperature $\left(\mathrm{T}^{-1}\right)$ versus grain size $\left(d_{g}\right)$ with time $(t)$ as $\ln \left(\Delta d_{g}^{2} \cdot t^{-1}\right)$. High-temperature isotope data ${ }^{[3-4]}$ delineate the transition between grain boundary and lattice diffusion mechanisms.

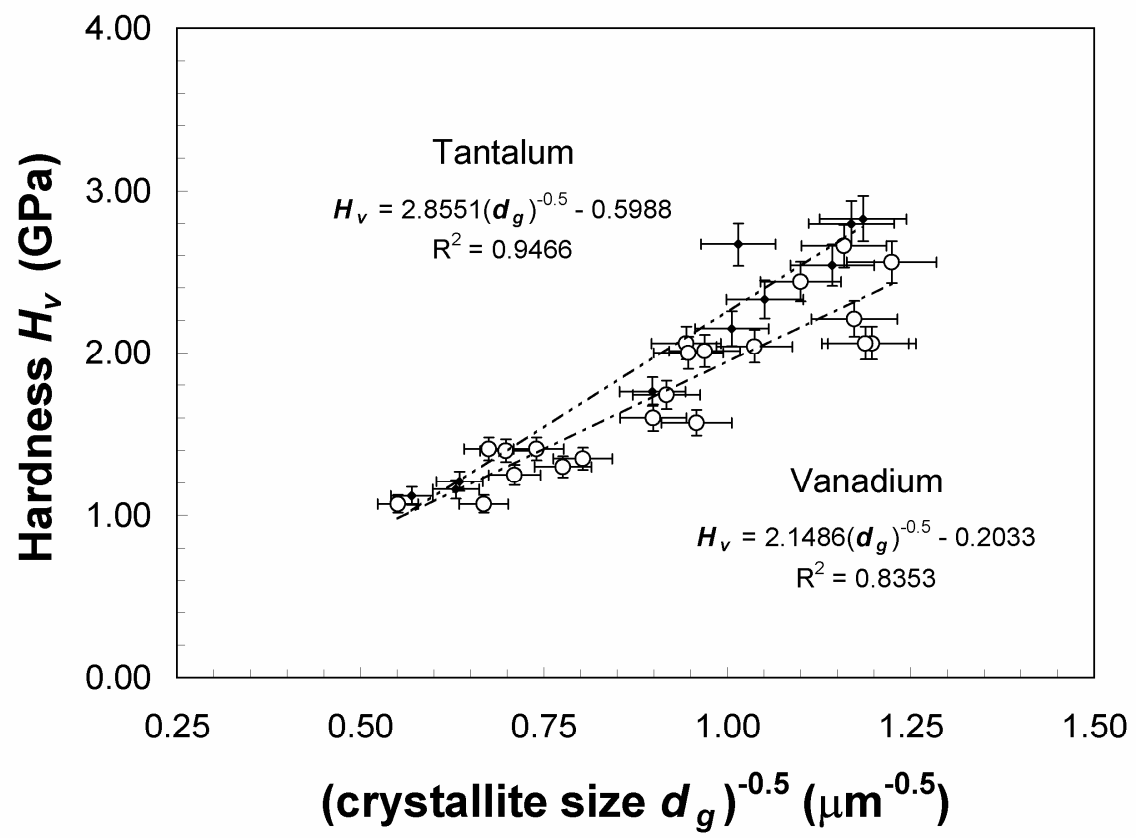

Figure 4. The variation of Vickers microhardness $\left(\mathrm{H}_{\mathrm{v}}\right)$ with the inverse-square root of grain size $\left(d_{g}{ }^{-0.5}\right)$ yield linear curves for both Ta and $\mathrm{V}$ foils over the grain size range of 0.7-4 $\mu \mathrm{m}$. 


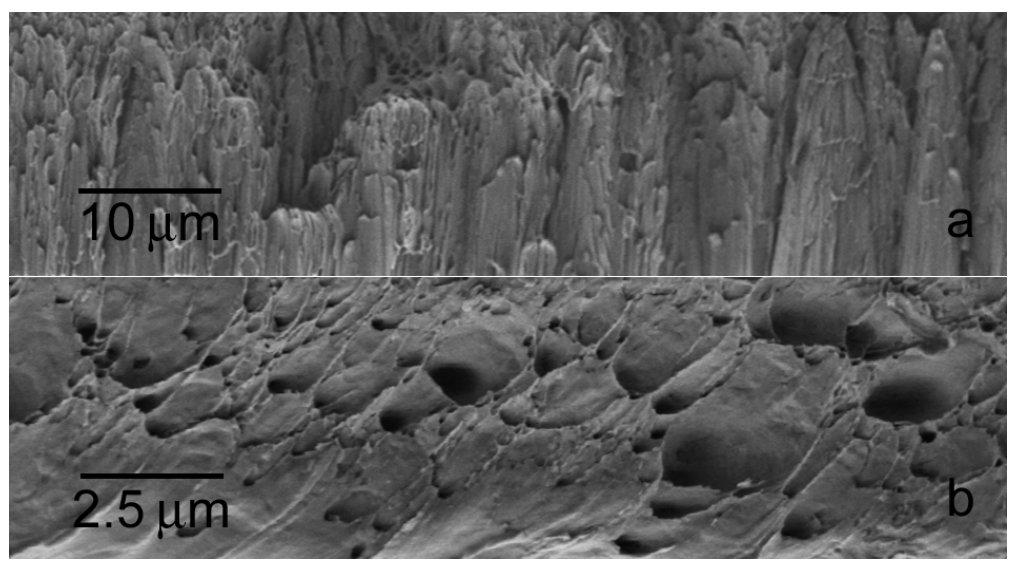

Figure 5. Scanning electron microscope images of the fracture cross-section to $15 \mu \mathrm{m}$ thick tensile specimens of $\mathrm{V}$ as prepared by (a) magnetron sputtering, and (b) electron-beam evaporation.

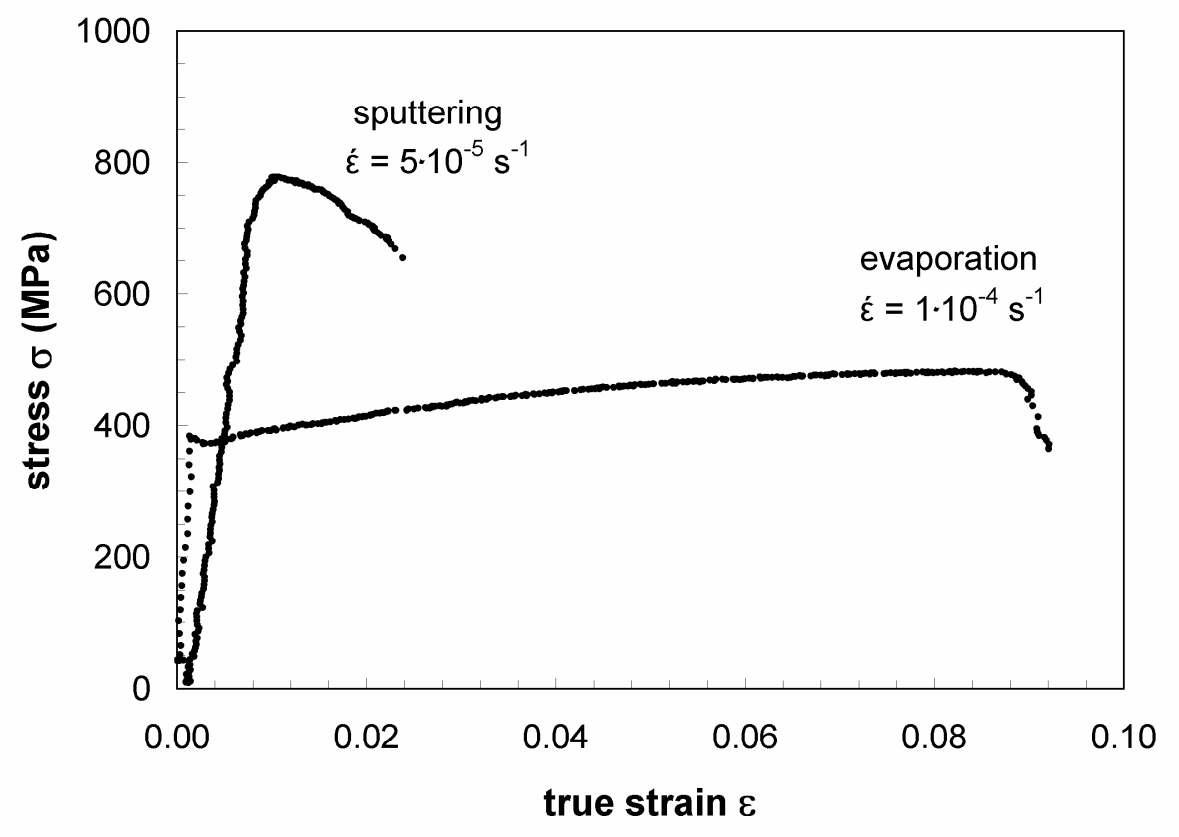

Figure 6. Engineering stress - strain curves for uniaxial tension tests at strain rates of $5 \cdot 10^{-5}$ to $1 \cdot 10^{-4}$ $\sec ^{-1}$ for $0.55 \mu \mathrm{m}$ grain size sputter deposited, and $1.61 \mu \mathrm{m}$ grain size electron-beam deposited $\mathrm{V}$ foils. 


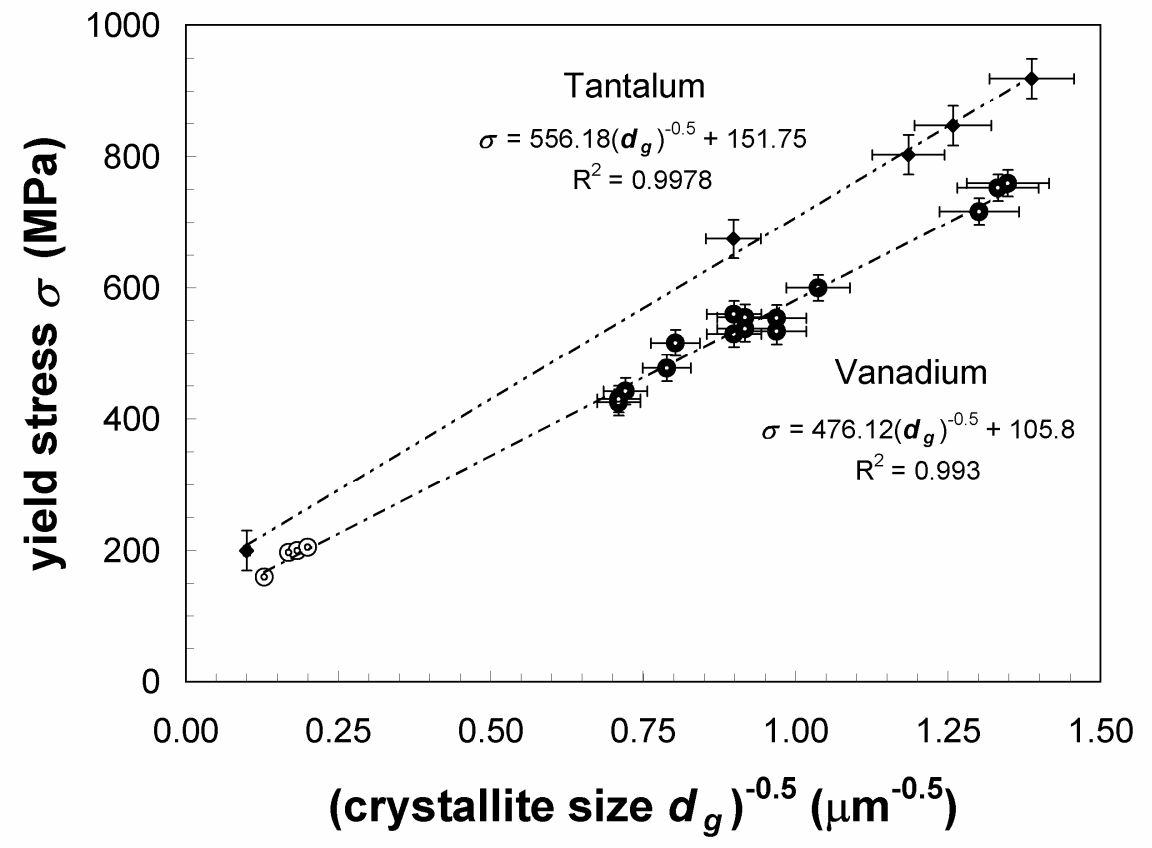

Figure 7. The variation of tensile strength $(\sigma)$ with the inverse-square root of grain size $\left(d_{g}^{-0.5}\right)$ yield linear curves for all $\mathrm{Ta}$ and $\mathrm{V}$ foils. 